\title{
A Study on the Communicative Competence of Indonesian Teachers at Bilingual Programs
}

\section{Heny Hartono}

Soegijapranata Catholic University, Indonesia

\begin{abstract}
Teachers' communicative competence should add the general teaching competencies of in-service teachers at bilingual programs. This challenges teachers to meet the standard of a competent speaker. Unfortunately, schools hardly assess teachers' communicative competence. This study aimed to find out the level of in-service teachers' communicative competence and the correlation among the level of communicative competence aspects. This sequential explanatory study involved 82 in-service teachers who taught in English. All of the participants participated in the quantitative data collection, and 12 of them were involved in the qualitative data collection. The results of this study reveal that the subjects of this study were found in the safe zone. It indicates that teachers of English speaking programs under this study can perform their tasks adequately, although they cannot be called competent yet. The Spearman correlational analysis found out that the coefficient correlation was above 0.76 , indicating a very strong correlation between the overall communicative competence and its aspects and strong positive correlations among the communicative competence aspects. The results of qualitative data analysis confirm that participants' communicative competence in each aspect of the communicative competence affects the overall communicative competence. The results of this study provide valuable input of teachers' communicative competence, which can be further followed up with suitable training to improve teacher's English competence.
\end{abstract}

\author{
ARTICLE HISTORY \\ Received 28 June 2020 \\ Accepted 18 August 2020 \\ Published 31 December 2020 \\ KEYWORDS: \\ In-service teachers, \\ communicative competence, \\ assessment
}

\section{Introduction}

Along with the prominent role of English as an international language, the number of English speakers is significantly increasing in the last few decades. English is claimed as a global language because of the number of its speakers and more on who the speakers are (Crystal, 2003). In Indonesia, English itself is one among other foreign languages such as Chinese and Arabic, which are commonly taught and used in this country. Using English as the medium of instruction in class can be challenging for local teachers within the foreign language context. As a foreign language, English is mostly taught as a subject at school. Teachers and students rarely use English as the medium of communication both inside and outside the classrooms. Teachers commonly use the national language or mixed language of Indonesian and English in delivering the English subject at schools. Thus, English is primary used in the classroom setting. In other words, the exposure to English as the target language is so little outside the classroom. With these facts, most schools do not use English as the medium of instruction except those which run English speaking programs such as bilingual or immersion programs.

The English speaking programs in Indonesia are commonly partial immersions with some variants of the curriculum. Some schools opt to use English in almost all subjects except for the Indonesian language, local (traditional) language, and other foreign languages. Several other schools only teach some 
subjects in the target language. Some of the subjects are mathematics, science, ICT (Information and Communication Technology) and arts. Mainly, schools prefer to teach mathematics and science in English to produce globally competitive graduates because mathematics and science are seen as the base for technology development.

Almost all Indonesian schools that offer immersion and bilingual programs include English as the language of instruction, although some also use other foreign languages such as Arabic, Mandarin, and French. Despite the attraction of other foreign languages, English as the most widely used international language has always been the most favourite target language of bilingual or multilingual schools. In fact, English has got its first place as foreign language in Indonesia. Educational institutions have caught this beneficial situation, especially from the private or non-government sector to open immersion programs. In reality, these programs are commonly found in big cities (capital city of provinces) in Indonesia. The use of English as the language of instruction has become a part of marketing strategies for private schools to get more students.

Nowadays, more and more schools open and offer immersion programs with various programs that sound marketable. Some labels are used to name the programs with attractive names such as "smart class", "special class", "international class", etc. The main characteristic of the programs is the use of English in some or all subjects at the schools. The schools may use national curriculum, modified curriculum or a curriculum which is adopted from other countries. These programs are different from international schools which have international students, use international curriculum, and use English as the main and only language of instruction.

Due to the high tuition fee and the expensive books used by the students, the target of immersion programs is middle-upper families. The facilities offered in this program are commonly above the ones of the regular programs. Usually, there are two teachers in one class and the classes are in small sizes where there are fewer students compared to the number of students in regular class. In basic education level, the classrooms are commonly designed in such a way to enable teacher and students have communicative interaction. Some schools may also hire native speakers of English to teach.

Some schools are under the category of transitional bilingual schools where L1 or mixed language is still used in the first years, but in the higher level, all content subjects are taught in English. Some others apply enrichment model in which students are expected to be bilingual and biliterate by having high proficiency in both languages as well as having cultural awareness in both languages. Thus, students are expected to be ready and able to participate in the global community because they can adapt themselves in the target language culture without losing their identity in the first language culture.

Teachers are one among other determining factors of the bilingual program's success. Therefore, teachers' communicative competence in the target language is important. In fact, due to several factors, not all teachers in these bilingual programs are communicatively competent. Teachers' educational background and experiences dealing with teaching in English are some among other factors which cause the lack of communicative competence. This study tried to see in-service teachers' communicative competence particularly their oral competence. Most of the discussion in this paper will be based on the aspects of communicative competence proposed by Celce-Murcia (2007). The result of this study provides a description of in-service teachers' communicative competence and a discussion on how the level of teachers' communicative competence may affect their performance as teachers of bilingual programs. In addition, this study also presented the results of correlational analysis among the levels of the teachers' communicative competence aspects.

\section{Methodology}

This research was designed as a sequential explanatory study that started with quantitative data analysis and qualitative data analysis. Creswell $(2008$, p. 211) mentions that this kind of research strategy is characterized by collecting and analysing quantitative data at the first phase and based on the result of the first phase, the qualitative method is employed at the second phase. Further, Creswell says, "A sequential explanatory design is typically used to explain and interpret quantitative results by collecting and analyzing follow-up qualitative data".

In this study, the quantitative data were collected through an assessment namely the communicative competence assessment. The in-service teachers' communicative competence level was measured with Communicative Competence Assessment tools. The tool had been developed by the writer 
in her previous Educational Research and Development Study. This instrument was adopted from communicative competence assessment designed by Pillar (2011). The communicative competence assessment was modified and developed based on the needs of communicative competence assessment for teachers. The Communicative Competence Assessment Tool consists of three assessment sets: selfassessment, receptive -productive assessment, and performance assessment. The results of the three components of communicative competence assessment give the final score indicating the participant's communicative competence level. The results of the assessment also show the participants' level in each aspect of communicative competence. Table 1 below describes the communicative competence level classification. In general, the communicative competence level is classified into five levels of competence.

Table1. Communicative Competence Band Descriptor

\begin{tabular}{|l|l|}
\hline $\begin{array}{l}\text { Final } \\
\text { Score }\end{array}$ & Description \\
\hline 1 & Intermittent Communicator: Communication occurs only sporadically. \\
\hline 2 & $\begin{array}{l}\text { Limited Communicator: Receptive/productive skills do not allow continuous } \\
\text { communication. }\end{array}$ \\
\hline 3 & $\begin{array}{l}\text { Moderate Communicator: Gets by without serious breakdowns. However, } \\
\text { misunderstandings and errors cause difficulties. }\end{array}$ \\
\hline 4 & $\begin{array}{l}\text { Competent Communicator: Copes well but has occasional misunderstandings } \\
\text { or makes occasional noticeable errors. }\end{array}$ \\
\hline 5 & Good Communicator: Copes well and performs competently. \\
\hline
\end{tabular}

This study involved 82 teachers from 6 schools that offered bilingual programs in Semarang, the capital city of Central Java Province. All of the participants contributed to the quantitative data collection while 12 were involved in the qualitative data collection. This research aimed to address the following research questions:

1. How is the communicative competence of in-service teachers at bilingual program?

2. Is there a significant correlation between each aspect of communicative competence and the overall communicative competence level? If yes, how is the correlation?

3. Is there a significant correlation among each aspect of communicative competence? If yes, how is the correlation?

The results of the communicative competence was quantitatively analysed with descriptive analysis to determine the participants' level of communicative competence. With this analysis, the writers also got the results of participants' level of communicative competence level in each aspect. Next, a correlation analysis using Spearman Rho was applied to see if there was a significant correlation among communicative competence aspects and the correlation between each aspect and the overall communicative competence level. The analysis was to prove the hypothesis that there was a significant correlation among each aspect of communicative competence and the overall communicative competence level and among each aspect of communicative competence. To confirm the results of the quantitative analysis, the writers also analysed the results of focus group discussion and in-depth interviews with 12 teachers as representatives of each school involved in this study.

\section{Results and Discussion}

Based on the assessment results, it can be concluded that overall, the in-service teachers' communicative competence under this study falls in Moderate level category. $2.44 \%$ of the respondents were categorized as intermittent communicators, $23.17 \%$ were limited communicators, $25.61 \%$ were moderate communicators, and $48.78 \%$ were considered competent communicators. With this result, it can be said that the in-service teachers under this study have been able to perform their role as teachers of bilingual programs. Although some errors still occasionally appear, it should not be major barriers for a classroom interaction. A complete data of the teachers' average communicative competence is presented in the following table: 
Table2. Result of Communicative Competence Assessment

\begin{tabular}{lllllllc}
\hline & LC & SoC & SC & FC & DC & IC & Overall \\
\hline Score & 3.5 & 3.7 & 3.7 & 2.9 & 3.6 & 3.6 & 3.5 \\
\hline
\end{tabular}

Overall, the results can be summarized in this following graph:

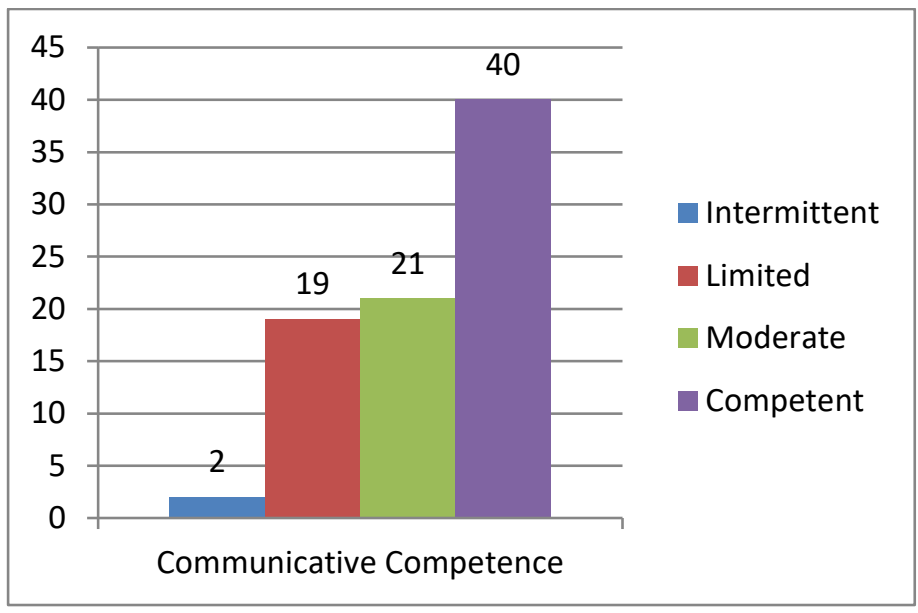

Graph 1. Communicative Competence Level

Interestingly, three out of the six schools involved in this study outperformed the other schools. The indepth interview results revealed that these schools run bilingual program in the form of immersion program. The teachers were recruited and prepared specifically for the bilingual programs. They graduated from English department or other majors with previous teaching experiences at international schools. Meanwhile, other schools did not recruit special teachers for the bilingual program. Those teachers were teachers from regular program who were assigned to teach their subjects in bilingual mode. Seen from the demographic data, 32 participants (36\% of the total participants) were English Department graduates and 50 participants (64\% of the total participants) were non-English Department graduates.

Referring to the result of communicative competence assessment in table 1, among the six aspects of communicative competence namely the linguistic competence, sociocultural competence, discourse competence, interactional competence, formulaic competence, and strategic competence, the weakest competence is the formulaic competence. The average of formulaic competence is 2.9 or under the limited level category. Meanwhile, the sociocultural and strategic aspects share the highest level of competence that the in-service teachers under this study achieve. In average, their communicative competence level is 3.5 or in moderate level. The following graph illustrates the teachers' communicative competence in each aspect.

The results of the correlational analysis (graph 2) among the variables of communicative competence aspects and the educational background indicate that there is a significant correlation between each single communicative competence aspect and the overall communicative competence. The statistics results of Spearman's rho show that the significant value (2 tailed) of each aspect towards the communicative competence is 0,00 or $<0,05$ meaning that there is a significant relationship between the communicative competence aspect and the overall competence. As shown in table 3 below, the correlation coefficients are between 0.76-0.99, indicating that the correlation is very strong at 0.01 significant level. 


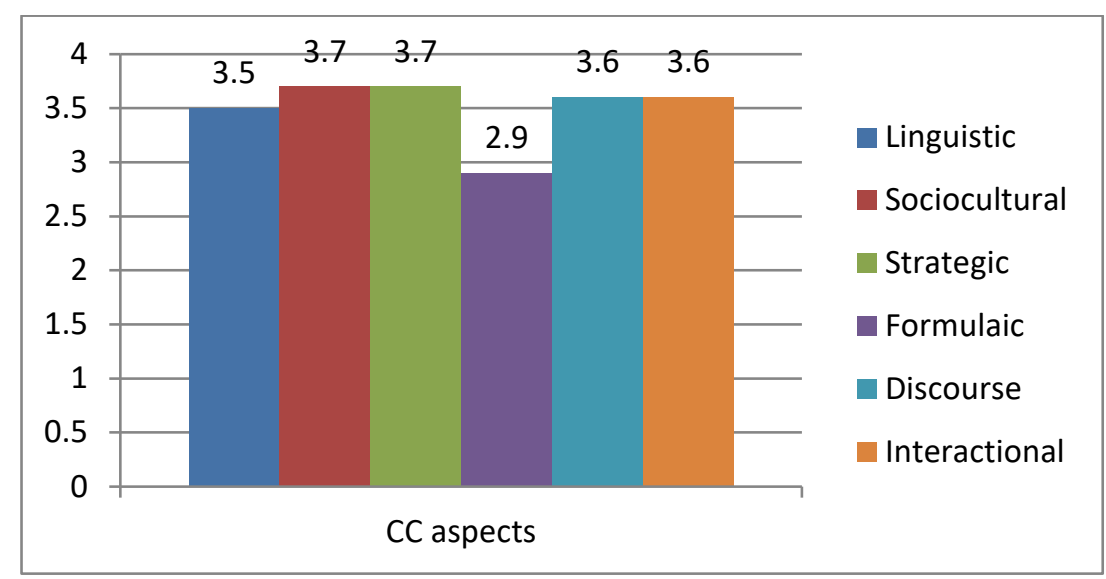

Graph 2. The Average Communicative Competence Aspects

The correlation coefficient of linguistics competence and the communicative competence is 0.939 meaning that the correlation is very strong and positive. It means that the higher linguistic competence level, the higher the communicative competence. Linguistics competence also has very strong relationships with other aspects of communicative competence. The coefficient correlation between linguistic competence and all other aspects of communicative competence is above 0.76 ( 0.766 for sociocultural competence, 0.866 for strategic competence, 0.791 for formulaic competence, 0.845 for discourse competence, and 0.841 for interactional competence) indicating very strong correlations. These results confirm that communicative language ability should cover the knowledge about the target language and how to use the target language. In other words, communicative competence is comprised of language proficiency and communicative proficiency. It confirms that language proficiency covers linguistic knowledge and the ability to use the language appropriately in various contexts (Abdurrahman and Abu Ayyash, 2019; Light \& McNaughton, 2014; Kumar, 2020). During the in-depth interview with the participants, the writers noted that most of the participants were worried about their limited vocabularies, their inability to pronounce English words accurately, and grammar in general.

As it can be seen from table 3 , the coefficient correlation of sociolinguistics competence and communicative competence is 0.796 which shows very strong correlation. This value is the least among other aspects but it still indicates that the correlation is very strong. Meanwhile, the correlation between sociocultural competence and other aspects of communicative competence is strong (0.698 for strategic competence, 0,718 for formulaic competence, 0.653 for discourse competence, and 0.54 for interactional competence). To be a competent speaker, the in-service teachers need to have knowledge of the target language sociocultural background. Their ability to adapt themselves with the target language culture affects their ability to communicate in the target language effectively. The sociocultural competence is gained through some stages, including learning from educational materials, gaining experiences, and demonstrating the ability (Safina, 2014). In the educational field, in-service teachers must demonstrate and perform their knowledge and skills related to sociocultural competence in their roles as educators.

The correlation between strategic competence and other aspects of competence also indicates strong and very strong correlation $(0.886$ for linguistic competence, 0.698 for sociocultural competence, 0.723 for formulaic competence, 0.803 for discourse competence, 0.816 for interactional competence). It confirms that to compensate for the communication breakdowns, non-native speakers need to have basic communicative abilities, including the other communicative competence aspects.

In general, there are significant correlations among the aspects of communicative competence although not all correlations indicate very strong relationship. The correlation is in positive mode indicating that the higher level of communicative competence aspect, the higher the communicative competence level. The results indicate that the hypothesis can be accepted. The results of qualitative data analysis confirm that participants' communicative competence in each aspect of the communicative competence affects their communicative competence in general. 
Table3. Correlational Analysis of Communicative Competence Aspects

Correlations

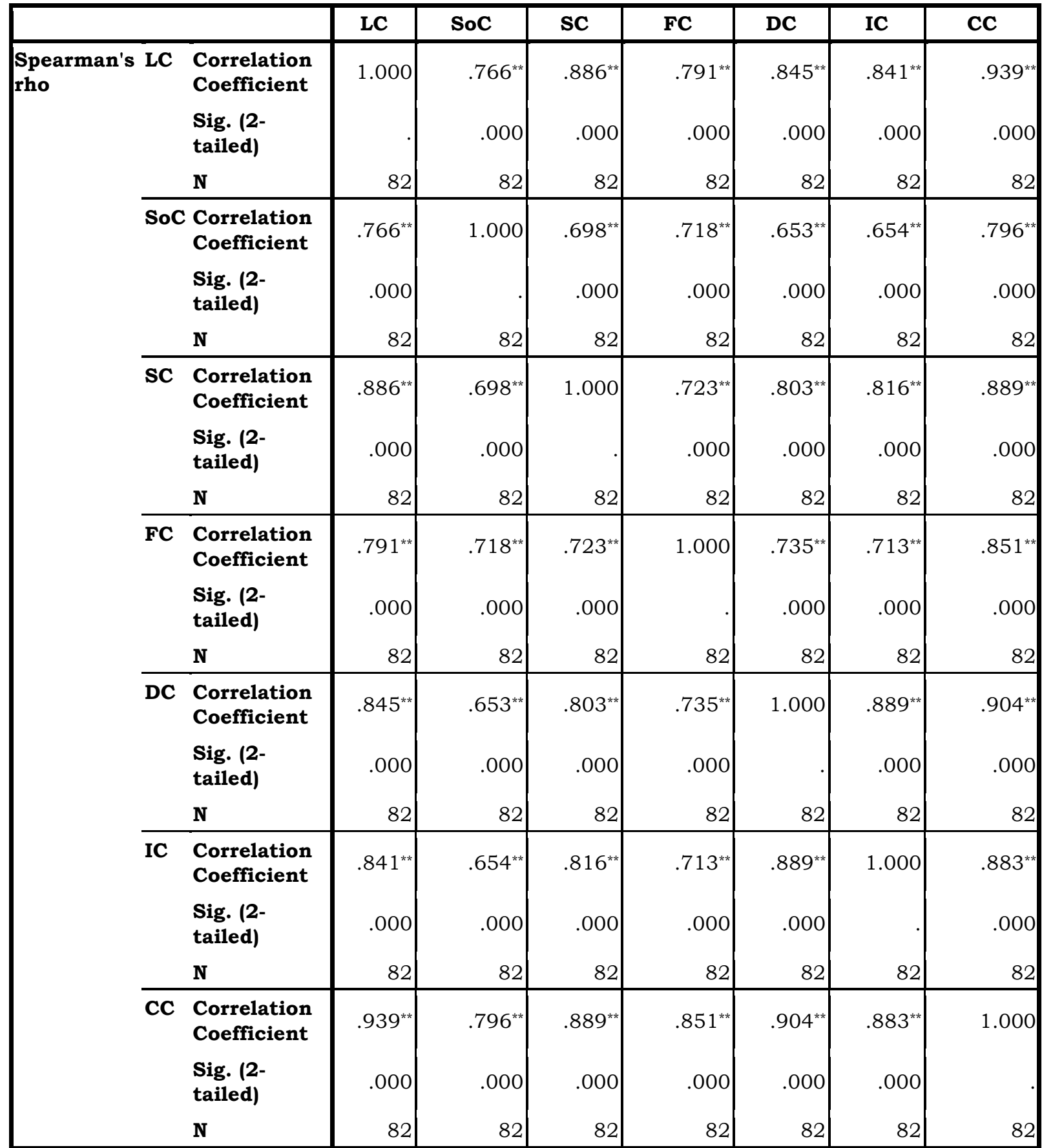

**. Correlation is significant at the 0.01 level (2-tailed).

\section{Implication}

Comparing the averages of each communicative competence aspect described in Graph 2 above, it seems that sociocultural and strategic competence share the same average and appears as the highest achieved competences among the other aspects of communicative competence. Sociocultural competence which is defined as the ability to use the language appropriately according to the sociocultural context (CelceMurcia, 2007) was generally copped well by the in-service teachers under this study. As teachers, they had 
been well trained to respect others and to respect differences. Moreover, with the socio-graphical background of Indonesia as an archipelago with thousands ethnics, Indonesian teachers get used to get along with others from different sociocultural background. In fact, it is just something common to learn the differences as well.

Another factor which may result in high level of communicative competence is the ability of the inservice teachers to articulate themselves in such a way to maintain the communication smooth. This ability refers to the strategic competence which allows the speakers to compensate the communication breakdowns. As teachers also use mime, non-verbal expression, and other means such as drawing and gestures while teaching, it seems that teachers know how to maintain the classroom communication. Teachers' ability to create a communicative communication in the classroom reflects their strategic competence.

Discourse, interactional, and linguistic competences are interrelated in which three of these communicative competence aspects challenge teachers' linguistic knowledge. Their ability and sensitivity to choose the right words for certain discourse or to perform certain speech acts as they practice the interactional competence, rely much on their language and grammatical knowledge. Tracing back to a few last decades, the English teaching practice in Indonesia was focused more on grammar teaching. Indonesian students used to learn English as a subject at school. This had led them to a good proficiency in written English. Good knowledge in language and grammatical often helps teachers in oral communication. However, oral communication needs more than just grammar mastery. Teachers are mostly confronted with oral communication when dealing with students in a classroom discourse. They need to be skillful in selecting and using appropriate words and expressions. As non-native speakers, teachers often feel insecure when handling an oral communication. Occhipinti (2009) also mentions that speaking activity tends to make someone feel insecure easily, especially if the speakers are not confident with their competences.

Reflecting to the level of each aspect, the writer's attention was drawn to the poor formulaic competence possessed by the in-service teachers. Ellis (1994) in his discussion about the developmental pattern of second language acquisition explains that similar to the first language acquisition, the second language acquisition also allows learners to follow order and sequence of developmental pattern. The use of formulaic expressions helps second language learners keep communication smooth especially in unplanned language use in which the second language speakers tend to deliberately pay attention to the language form by using explicit language or grammatical knowledge or by translating (Ellis, 1994). In unplanned language use, teachers tend to translate from the first language to the target language. It is even worse when they translate word by word. If only they can apply formulaic speech that consists of fixed and memorized chunks, they will overcome their nervousness in unpredictable situations such as when students ask something out of the context or when the interaction with students develops into more intimate and intensive conversation.

Native speakers commonly use the formulaic speech itself as reflection of language behavior. It consists of routines, patterns, lexical phrases, or even longer expressions such as fixed and predictable greetings. Pawley and Seyder (1983 as cited in Ellis, 1994, p.85) maintain that "achieving native-like control involves not only learning a rule system but also memorized sequences and lexicalized sentence stem". Practices that stimulate the use of formulaic speech can boost teachers' formulaic competence. A list of everyday or classroom expressions is recommended to teachers. Teachers may also enrich their bank of expressions by watching some online English tutorials in you tube. The more memorized chunks they have, the easier they compensate with communication breakdowns. In other words, the formulaic speech can help teachers develop their formulaic competence and strategic competence. In fact, it can lessen their burden when dealing with unplanned or unexpected situations which challenge them to keep the communication going. The memorized expressions can also help teachers develop their linguistic competence because they can refer to the structure of the fixed expressions they use. Moreover, they can also learn about the target culture through the expressions, when and how the expressions are said appropriately within certain discourse.

Up to this point, the writer argues that formulaic competence is crucial for a second language speaker. Teachers of bilingual program can be trained to equip themselves with formulaic speech. The formulaic speech can help teachers survive in unpredictable language use.

In relation to teachers' professional development, English training that focuses on communicative competence enhancement can support teachers' professional competence. Therefore, the results of this 
study may describe how the level of in-service teachers' communicative competence was, especially the oral communicative competence which was crucial to support the teaching and learning process. It is in line with the common perception that for non-native speakers, speaking skill is often seen as the most important and even the most difficult skill to acquire (Young, 1990). Further, designing effective teacher professional development programs including training or workshops, should consider the teachers' needs to improve the quality of the education (Lear, 2019).

\section{Results and Discussion}

The results of this study reveal that the subjects of this study were found in safe zone. It indicates that teachers of bilingual programs under this study can perform their tasks adequately, yet they cannot be called competent. Most of them can handle classroom routines such as opening the class with greetings, delivering the materials, and closing the classes. However, they still find difficulties and make mistakes in unpredicted situations, such as when students ask questions or give students feedback. The study results can be a reference for schools with bilingual programs to maintain and improve teachers' communicative competence through professional training. Schools may schedule periodic trainings as a part of teacher's professional development. This study was limited in participant number and the area of research setting. For further research, a bigger number of teachers from wider range of area can be considered. In addition, it will also be beneficial if a similar study is conducted with pre-service teachers as the participants in the future.

\section{References}

Abdulrahman, N. C. ., \& Ayyash , E. A. S. A.-. (2019). Linguistic competence, Communicative Competence and Interactional Competence. JOURNAL OF ADVANCES IN LINGUISTICS, 10, 16001616. https://doi.org/10.24297/ial.v10i0.8530

Celce-Murcia, M. (2007). Rethinking the Communicative Competence in Language Teaching. In E. A. Soler, $\&$ M. P. Jorda, Intercultural Language Use and Language Leraning (pp. 41-57). Dordrecht: Springer.

Cresswell, J. W. (2008). Research Design: Qualitative, Quantitative, and Mixed Methods Approaches. 3rd Edition. California: SAGE publication.

Crystal, D. (2003). English as a Global Language. New York : Cambridge University Press.

Ellis, R. (1994). The Study of Second Language Acquisition. New York: Oxford University Press.

Kumar, T. (2020). Assessing Language Need and Proficiency of English Graduates of Prince Sattam Bin Abdulaziz University for Designing Pre-Placement Training and Workshops. The Asian ESP Journal. July 16 (4 9). 153 - 168

Lear, M.F. (2019). Voices of English Teachers on Professional Development. The Asian ESP Journal. June 15 (1.2), 198-224.

Light, J \& McNaughton, D. (2014). Communicative Competence for Individuals who require Augmentative and Alternative Communication: A New Definition for a New Era of Communication?. Augmentative and Alternative Communication, 30(1), 1-8.

Minnisa, S. S. (2014). Formation of Socio-Cultural Competence in Foreign Language Teaching. Procedia Social and Behavioral Sciences. 136 (2014) $80-83$.

Occhipinti, A. (2009). Foreign Language Anxiety in in-Class Speaking Activities Acknowledgments. Foreign Language Anxiety in In-Class Speaking Activities, 1-112.

Pilar, G. (2011). A Framework for Testing Communicative Competence. Partium Journal of English Studies, 2(1). 24-37.

Young, D. J. (1990). An Investigation of Students' Perspectives on Anxiety and Speaking. Foreign Language Annals. 23(6). 539-567 